University of Nebraska - Lincoln

DigitalCommons@University of Nebraska - Lincoln

September 1996

\title{
Magnetization Reversal Behavior in Cobalt Rare-Earth Thin Films
}

\author{
S.S. Malhotra \\ University of Nebraska - Lincoln \\ Z.S. Shan \\ University of Nebraska - Lincoln \\ D.C. Stafford \\ University of Nebraska - Lincoln \\ Sy_Hwang Liou \\ University of Nebraska-Lincoln, sliou@unl.edu \\ David J. Sellmyer \\ University of Nebraska-Lincoln, dsellmyer@unl.edu
}

Follow this and additional works at: https://digitalcommons.unl.edu/physicssellmyer

Part of the Physics Commons

Malhotra, S.S.; Shan, Z.S.; Stafford, D.C.; Liou, Sy_Hwang; and Sellmyer, David J., "Magnetization Reversal Behavior in Cobalt Rare-Earth Thin Films" (1996). David Sellmyer Publications. 75.

https://digitalcommons.unl.edu/physicssellmyer/75

This Article is brought to you for free and open access by the Research Papers in Physics and Astronomy at DigitalCommons@University of Nebraska - Lincoln. It has been accepted for inclusion in David Sellmyer Publications by an authorized administrator of DigitalCommons@University of Nebraska - Lincoln. 


\title{
Magnetization Reversal Behavior in Cobalt Rare-Earth Thin Films
}

\author{
S. S. Malhotra, Z. S. Shan, D. C. Stafford, S. H. Liou, and D. J. Sellmyer \\ Behlen Laboratory of Physics and Center for Materials Research and Analysis \\ University of Nebraska, Lincoln, NE 68588-0111
}

\begin{abstract}
Cobalt Rare-Earth (CoR, $R=P r, S m)$ thin films on a $\mathrm{Cr}$ underlayer have shown promise as future ultra high density magnetic recording media. The activation volume or the magnetic switching volume $\left(V^{*}\right)$ is an important consideration for thermal stability and media noise in high density recording media and $V^{*}$ can also provide information about the magnetization reversal behavior in these films. The magnetic switching volume was estimated for the CoPr films with thicknesses from 28 to $639 \mathrm{~nm}$ with a $\mathrm{Cr}$ underlayer of 80 $\mathrm{nm}$ annealed at $500{ }^{\circ} \mathrm{C}$. The measured switching volume ranges from 1.3 to $1.7 \times 10^{-18} \mathrm{~cm}^{3}$. We have also studied the $\mathrm{Cr}$ underlayer thickness and temperature effects on the swithcing volume for the CoSm films.
\end{abstract}

\section{INTRODUCTION}

$\mathrm{CoSm}$ films with a $\mathrm{Cr}$ underlayer prepared at room temperature with high magnetic coercivity $\left(\mathrm{H}_{\mathrm{c}}\right)$ of about $3-4$ $\mathrm{kOe}$ [1]-[3] and annealed CoPr films on $\mathrm{Cr}$ underlayer with $\mathrm{H}_{\mathrm{c}}$ of up to $10 \mathrm{kOe}$ [4] have shown promise as future high density recording media. It has been shown that the grain size in high density recording media significantly influences the media noise and thermal stability $[5,6]$. However, it should be emphasized that the magnetic grain rather than the structural grain is responsible for these characteristics. For example, the switching volume $\left(\mathrm{V}^{*}\right)$ may be much larger than the structural grain if the interactions between the structural grains are strong enough to make them undergo reversal together. Therefore $\mathrm{V}^{*}$, is an important consideration for understanding the magnetization reversal in high density recording media. The magnetic switching volume can be obtained by measuring the coercivity as a function of the sweep rate of the applied field and also through magnetic viscosity and remanence measurements. Singleton et al. [7] reported measurements of $\mathrm{V}^{*}$ on the order of $10^{-18} \sim 10^{-17} \mathrm{~cm}^{3}$ for CoSm films depending on the $\mathrm{CoSm}$ film thickness, $\mathrm{Cr}$ underlayer thickness and $\mathrm{Ar}$ sputtering pressure. The diameters of the magnetic.grains calculated from the measured switching volume for the $\mathrm{CoSm}$ layer at room temperature were in the range of 14 to $26 \mathrm{~nm}$ which are roughly similar to the average size of the $\mathrm{Cr}$ underlayer grains as determined by transimission electron microscopy (TEM).

Manuscript received March 4, 1996 . S. S. Malhotra, email malhotra@unlinfo.unl.edu, D. J. Sellmyer, email:cmra@unlinfo.unl.edu, fax 402-472-2879. The work was supported by ARPANSIC under Grant No. MDA972-93-1.0009 and NSF under Grant OSR-9255525 and Grant DMR-9222976
In this work the magnetic switching volume was measured for a series of CoPr films with thicknesses from 28 to 639 $\mathrm{nm}$ with an underlayer of $80 \mathrm{~nm}$ annealed at $500{ }^{\circ} \mathrm{C}$. Here we also report the results of the dependence of the switching volume for CoSm films with and without a $\mathrm{Cr}$ underlayer as a function of temperature from 50 to $300 \mathrm{~K}$. The switching volume is correlated to the magnetic properties and microstructure of the films.

\section{EXPERIMENT}

$\mathrm{CO}_{78} \mathrm{R}_{22}$ films were prepared by dc magnetron sputtering from composite targets. The CoR targets were made of pressed and sintered powders and the $\mathrm{Cr}$ target was obtained commercially and had a purity of $99.9 \%$. The Ar pressure during sputtering for $\mathrm{CoSm} / / \mathrm{Cr}$ films was $7 \mathrm{mTorr}$ for the $\mathrm{Cr}$ underlayer and $25 \mathrm{mT}$ Torr for the CoSm layer. For the $\mathrm{CoPr} / / \mathrm{Cr}$ films the sputtering pressure was $20 \mathrm{mT}$ Torr of $\mathrm{Ar}$ gas. The sputtering rate for CoPr and CoSm was $0.1 \mathrm{~nm} / \mathrm{sec}$. and for $\mathrm{Cr}$ was $0.5 \mathrm{~nm} / \mathrm{sec}$. The magnetic properties of the films were measured using an Alternating Gradient Force Magnetometer. The sweep rate of the magnetic field was varied from $50 \mathrm{Oe} / \mathrm{s}$ to $10,000 \mathrm{Oe} / \mathrm{s}$ and coercivity changed as a function of the sweep rate. During viscosity measurements, a maximum field of $14 \mathrm{kOe}$ was applied to saturate the films magnetization. A reverse field near the coercive field was then applied and the magnetization was measured as a function of time. The irreversible susceptibility $\chi_{\text {irr }}$ was derived from the dc demagnetization curves.

\section{RESULTS AND DISCUSSIONS}

We first discuss the measured switching volume for the $\mathrm{CoPr} / / \mathrm{Cr}$ films with a $\mathrm{Cr}$ underlayer of $80 \mathrm{~nm}$ annealed at $500{ }^{0} \mathrm{C}$. The as-deposited $\mathrm{CoPr} / / \mathrm{Cr}$ films are mostly amorphous and then crystallized by annealing at $500{ }^{\circ} \mathrm{C}$. The as-deposited films show a $\mathrm{H}_{\mathrm{c}}$ of only about 100-300 Oe but after annealing at $500^{\circ} \mathrm{C}$ the $\mathrm{H}_{\mathrm{c}}$ of the films ranges from $10 \mathrm{kOe}$ to $5.9 \mathrm{kOe}$ as the film thickness increases from 28 $\mathrm{nm}$ to $639 \mathrm{~nm}$. The $28 \mathrm{~nm}$ thick CoPr film annealed at 500 ${ }^{0} \mathrm{C}$ was nearly $100 \%$ crystalline with a grain size of $10 \mathrm{~nm}$ resulting in the large increase in the coercivity [4]. The switching volume was measured by the dependence of apparent coercivity on the sweep rate of the magnetic field and also by magnetic viscosity and remanence measurements for some of the samples. 
The coercivity as a function of the sweep rate of the magnetic field is given by [8],[9],

$$
H_{c}=C+\left[\frac{k_{B} T}{V^{*} M_{s}}\right] \ln \left[\frac{d H}{d t}\right]
$$

where $\mathrm{C}$ is a constant independent of the field-sweep rate. The switching volume can be obtained from the slope of $\mathrm{H}_{0}$ vs. $\ln (\mathrm{dH} / \mathrm{dt})$ plot. Figure 1 shows the dependence of $\mathrm{H}_{\mathrm{c}}$ on $\ln (\mathrm{dH} / \mathrm{dt})$ for different CoPr layer thicknesses. All the samples exhibit the approximate linear relation of $\mathrm{H}_{c}$ on $\ln (\mathrm{dH} / \mathrm{dt})$. Measurements at higher sweep rates give a larger value of $\mathrm{H}_{\mathrm{c}}$ than a lower sweep rate measurement. The measured switching volume values are given in Table 1 and $\mathrm{V}^{*}$ is on the order of 1.3 to $1.7 \times 10^{-18} \mathrm{~cm}^{3}$.

The switching volume was also determined for some samples by the time decay of magnetization and remanence curve measurements. In many materials it is found experimentally that the change in magnetization often follows the relation [10],

$$
M(H, t)=M\left(H, t_{0}\right)+S(H) \ln (t)
$$

where $\mathrm{M}$ is the net magnetization, $\mathrm{S}$ the viscosity coefficient, and $t$ the time elapsed since the last field change. The effective fluctuation field is given by [10],[11],

$$
H_{f}=\frac{S}{\chi_{i r r}}=\frac{k_{B} T}{V^{*} M_{s}}
$$

The maximum value of $S$ and $\chi_{\text {in }}$ reflect the behavior of the most numerous energy barriers and are generally found near the coercive field. In effect this means that the coercivity characterizes the switching of the most grains in the sample. The viscosity coefficient $S$ is obtained from the plot of $\mathrm{M}(\mathrm{H}, \mathrm{t})$ vs. $\ln (\mathrm{t})$.

Figure 2 shows the dependence of $S$ vs. applied field and the peak value of $\mathrm{S}$ is around $7500 \mathrm{Oe}$. The irreversible

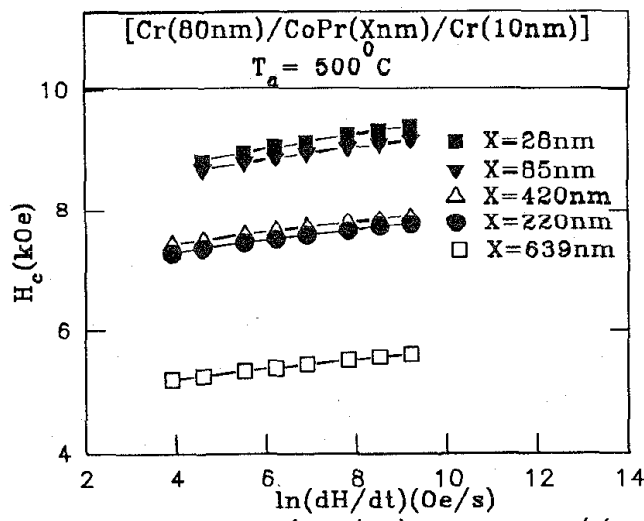

Fig. 1: $H_{e}$ vs $\ln (d H / d t)$ for $\mathrm{CoPr} / / \mathrm{Cr}$ film.

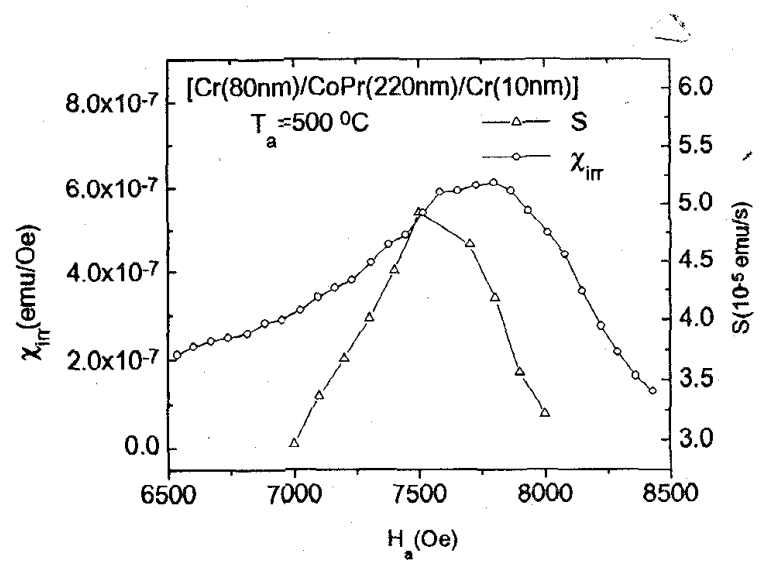

Fig. 2: Viscosity coefficient ( $(\$)$ \& irreversible suseptibility $\chi_{\text {irr }}$ as a function of field for CoPr/Cr film.

susceptibility $\chi_{\text {irr }}$ is derived from the dc demagnetization remanence curve $\left(\chi_{\text {irr }}=\mathrm{dM}_{\mathrm{d}} / \mathrm{dH}\right)$. Figure 2 also shows the dependence of $\chi_{\text {irr }}$ vs. applied field for the sample. The switching volume estimated from the maximum value of $\chi_{\text {ir }}$ and $S$ was found to be about $1.8 \times 10^{-18} \mathrm{~cm}^{3}$. Table 1 gives the values of $\mathrm{V}^{*}$ for three different samples. The switching volume estimated by both of these methods have rather similar values which suggests that the $V^{*}$ values in Table 1 are acceptable in analyzing the process of magnetization reversal.

The magnetic switching volume for the $28 \mathrm{~nm}$ thick $\mathrm{CoPr}$ film is on the order of $1.3 \times 10^{-18} \mathrm{~cm}^{3}$. The anisotropy $\mathrm{K}_{\mathrm{u}}$ is $4 \sim 5 \times 10^{6} \mathrm{erg} / \mathrm{cm}^{3}$ for this film. Therefore the requirement for thermal stability in high density recording, i.e. $\mathrm{K}_{\mathrm{u}} \mathrm{V}^{*} / \mathrm{k}_{\mathrm{B}} \mathrm{T}>100$, is satisfied. Using this value and the film thickness, the diameter of the magnetic grain can be estimated assuming that it is a cylindrical cell whose height is the thickness of the CoPr film. The magnetic grain diameter is about $8 \mathrm{~nm}$ and the magnetization reversal takes place roughly in the unit of the CoPr grains $(\sim 10 \mathrm{~nm}$ in dimensions as determined by TEM [4]). The magnetic switching volume $\mathrm{V}^{*} \approx(8 \mathrm{~nm})^{3}$ for the $28 \mathrm{~nm}$ thick film is sufficient for both the thermal stability and noise

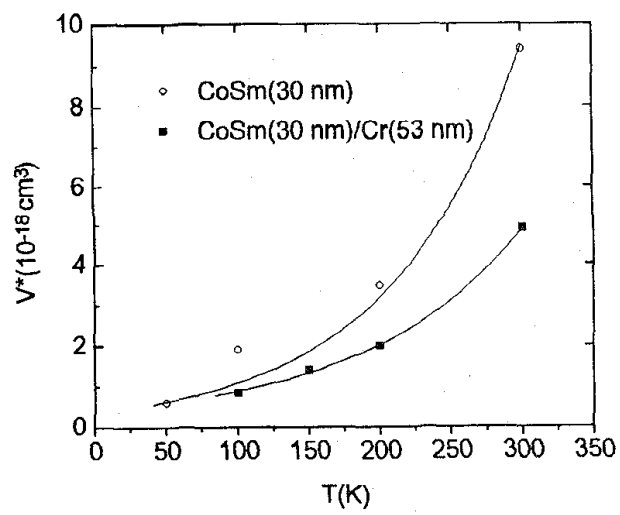

Fig. 3. Magnetic Switching volume as a function of $\mathrm{T}$. 
Table 1. Magnetic Switching Volume vs. PrCo Thickness

\begin{tabular}{|c|c|c|c|}
\hline $\begin{array}{l}\operatorname{PrCo}(\mathrm{Xnm}) / / \mathrm{Cr}(80 \mathrm{~nm}) \\
\mathrm{T}_{\mathrm{a}}=500{ }^{\circ} \mathrm{C}\end{array}$ & $\mathrm{H}_{\mathrm{c}}(\mathrm{Oe})$ & $\begin{array}{l}\mathrm{V}^{*} \text { (Determined } \\
\text { by sweep rate } \\
\text { dependence) }\end{array}$ & $\begin{array}{l}\mathrm{V}^{*} \text { (Determined by Time } \\
\text { Decay and irreversible } \\
\text { susceptibility) }\end{array}$ \\
\hline $\mathrm{x}=28 \mathrm{~nm}$ & 9,150 & $1.3 \times 10^{-18} \mathrm{~cm}^{3}$ & --- \\
\hline $\mathrm{x}=85 \mathrm{~nm}$ & 8,950 & $1.6 \times 10^{-18} \mathrm{~cm}^{3}$ & - \\
\hline $\mathrm{x}=220 \mathrm{~nm}$ & 7,570 & $1.4 \times 10^{-18} \mathrm{~cm}^{3}$ & $1.8 \times 10^{-18} \mathrm{~cm}^{3}$ \\
\hline $\mathrm{x}=420 \mathrm{~nm}$ & 7,710 & $1.5 \times 10^{-18} \mathrm{~cm}^{3}$ & $1.4 \times 10^{-18} \mathrm{~cm}^{3}$ \\
\hline $\mathrm{x}=639 \mathrm{~nm}$ & 5,450 & $1.7 \times 10^{-18} \mathrm{~cm}^{3}$ & $2.8 \times 10^{-18} \mathrm{~cm}^{3}$ \\
\hline
\end{tabular}

considerations. The $28 \mathrm{~nm}$ thick PrCo film with a larger coercivity value compared to the $639 \mathrm{~nm}$ thick PrCo film has a smaller switching volume. Both $\mathrm{H}_{c}$ and $\mathrm{V}^{*}$ are related to the magnetization reversal mechanisms which depend on the microstructure.

It is of interest to consider the magnetic switching volume for $\mathrm{CoSm}$ films as a function of temperature. Figure 3 shows $\mathrm{V}^{*}$ measured by the sweep rate dependence of the applied field at temperatures from 50 to $300 \mathrm{~K}$ for $\mathrm{CoSm}$ films with and without the $\mathrm{Cr}$ underlayer. The $\mathrm{H}_{\mathrm{c}}$ of the $30 \mathrm{~nm}$ thick $\mathrm{CoSm}$ film with a $\mathrm{Cr}$ underlayer of $53 \mathrm{~nm}$ is about $3.1 \mathrm{kOe}$ and for the $30 \mathrm{~nm}$ CoSm film without the $\mathrm{Cr}$ underlayer the $\mathrm{H}_{\mathrm{c}}$ is about $1.6 \mathrm{kOc}$. It is seen that at room temperature the $\mathrm{V}^{*}$ for the CoSm with the $\mathrm{Cr}$ underlayer is smaller than that of the film with no $\mathrm{Cr}$ underlayer. This is because the $\mathrm{Cr}$ underlayer develops the columnar morphology which is replicated by the $\mathrm{CoSm}$ layer and provides magnetically isolated grains in the $\mathrm{CoSm}$ layer. The absence of a $\mathrm{Cr}$ underlayer allows for larger magnetic interactions and an increased switching volume for the CoSm films. Liu et al.[12] have observed that for $\mathrm{CoSm} / / \mathrm{Cr}$ films the $\mathrm{Cr}$ underlayer has a grain size of about $24 \mathrm{~nm}$ and the CoSm layer consists of nanocrystallites of about $5 \mathrm{~nm}$ embedded in an amorphous matrix. At room temperature the magnetic grain diameter determined from the measured $\mathrm{V}^{*}$ for the $\mathrm{CoSm} / / \mathrm{Cr}$ films is on the order of the average grain size of the $\mathrm{Cr}$ underlayer. Thus the reversal of magnetization occurs in switching units of dimensions of the $\mathrm{Cr}$ grains.

It is also seen from Fig. 3 that the $\mathrm{V}^{*}$ decreases at lower temperatures for both of the samples. This temperature dependant behavior has been reported by Singleton et al.[7] and Givord et al.[13] and may be used to obtain information about the reversal mechanism. A temperature independant value of $\mathrm{V}^{*}$ would correspond to coherent rotation of single domain particles. The decrease of $\mathrm{V}^{*}$ with decreasing temperature suggests that the switching mechanism is more complicated and may involve incoherent rotation. Our further work on these samples shows a wall-pinning reversal mechanism which will be reported in detail in a paper to be published.

\section{REFERENCES}

[1] E. M. T. Velu and D. N. Lambeth, " CoSm-based high coercivity thin films for longitudinal recording", J. Appl. Phys., vol. 69, pp. 5175-5177, 1991.

[2] Y. Okumura, H. Fujimori, O. Suzuki, N. Hosoya, X. B. Yang, and $\mathrm{H}$. Morita, "Magnetic properties and microstructure of sputtered $\operatorname{CoSm} / \mathrm{X}(\mathrm{X}=\mathrm{Ti}, \mathrm{V}, \mathrm{Cu}, \mathrm{Cr})$ thin films", IEEE Trans. Magn., vol. 30, pp. 4038-4040, 1994.

[3] D. J. Sellmyer, Z. S. Shan, Y. Liu, S. H. Liou, S. S. Malhotra, and B. W. Robertson, "Magnetic and structural properties of high coercivity nanocrystalline $\mathrm{CoSm}$ films with in-plane anisotropy", Scripta Met. and Mat., vol.33, pp. 1545-1552, 1995.

[4] S. S. Malhotra, Y. Liu, Z. S. Shan, S. H. Liou, D. C. Stafford, and D. J. Sellmyer, "High coercivity rare earth-cobalt films", J. Appl. Phys., in press.

[5] M. P. Sharrock, " Time-dependant magnetic phenomena and particle size effect in recording media", IEEE Trans. Magn., vol. 26, pp. 193-197, 1990.

[6] P. Lu and S. H. Charap, "Magnetic viscosity in high-density recording," J. Appl. Phys. vol. 75, pp. 5768-5770, 1994.

[7] E. W. Singleton, Z. S. Shan, Y. S. Jeong, and D. J. Sellmyer, "Magnetic switching volume of CoSm thin films for high density longitudinal recording", IEEE Trans. Magn., vol. 31, pp. 2743-2745, 1995.

[8] P. Bruno, G. Bayreuther, P. Beauvillian, C. Chappert, G Lugert, D. Renard, J. P. Renard, and J. Seiden, " Hysteresis properties of ultrathin ferromagnetic films", J. Appl. Phys., vol. 68 , pp. 5759-5761, 1990.

[9] T. Suzuki, "Coercivity mechanism in (Co/Pt) and (Co/Pd) multilayers", Scripta. Met. and Mat., vol. 33, pp. 1609-1624 1995.

[10] R. Street, and J. C. Woolley, "A study of magnetic viscosity", Proc. Phys. Soc. Sect. A, vol.62, pp. 562-572, 1949.

[11] E. P. Wohlfarth, " The coefficient of magnetic viscosity", J. Phys. F: Met. Phys. vol.14, pp. L155-159, 1984.

[12] Y. Liu, B. W. Robertson, Z. S. Shan, S. S. Malhotra, M. J. Yu, S. K. Renukunta, S. H. Liou, and D. J. Sellmyer, "Nanostructure of Sm-Co on Cr thin films", IEEE Trans. Magn., vol. 30, pp. 4035-4037, 1994.

[13] D. Givord, Q. Lu, M. F. Rossignol, P. Tenard, and T. Vaidieu, "Experimental approach to coercivity analysis in hard magnetic materials", J. Mag. Mag. Mat., vol. 83, pp. 183-188, 1990. 